\title{
SOCIAL MEDIA AND DIGITAL FUTURES IN INDIAN COVID - 19 ERA
}

\author{
Dr. Tanu Kathuria \\ Associate Professor \& Head: UG Department, School of Management \\ Model Institute of Engineering \& Technology (Autonomous) \\ Jammu, India
}

\begin{abstract}
The present paper addresses the importance of Social Media platforms during pandemic. It has been discussed as to how social media platforms have been a key piece for the dissemination of information as never in human history earlier, it has been possible to communicate so quickly. Its usage has shown to increase in situations of natural disaster and other crises. Responsible use of these tools can help quickly disseminate important new information, relevant new scientific findings, share diagnostic, treatment, and follow-up protocols, as well as compare different approaches globally, removing geographic boundaries for the first time in history. Through social media communication, the scientific community got enabled to collaborate, coordinate research and knowledge, around the globe in a faster way and enhance their capabilities to make a more resilient community. Following the descriptive methodology, paper attempts to list out the points as to how during the 2020 global pandemic, social media has become an ally but also a potential threat and how effective as a tool it is during present pandemic. How effectively social media is circulating the most important findings of a disease, with a decreased knowledge transition time to other healthcare providers (HCPs) is documented in detail in the paper. It is further documented as to how the high volumes of information compressed into a short period can result in overwhelmed HCPs trying to discern fact from noise. For the ease in practice and in the research, to use these tools in a responsible and useful way, it is recommended to follow some basic guidelines when sharing information on social networks in the COVID-19 era. In this paper, we summarize the most relevant information on the influence, advantages, and disadvantages of the use of social networks during the COVID-19 pandemic. Also, the present study deals with the importance of digital space and the impact of digitization to deal with the health crisis and economic crises in tandem. Further the paper attempts to list down the key issues that are important for research and practice and concludes that there is an opportunity to grow as digital scientific community as well as digital lay public by equipping them with the required resources and accesses to deal with the post COVID -19 scenario which is a digital form of present scenario.
\end{abstract}

Keywords: India, Covid-19, Social Media, Digital Future, Pandemic, Health Crises

\section{INTRODUCTION}

Social media platforms are amongst the most widely used sources of information in the World, the easy and inexpensive access to the internet and many registered users in these platforms make them one of the easiest and most effective ways to disseminate information (Daniel et al., 2020). During major events, the overall response is usually a greater search for information be it a sports event, a disease, or a natural disaster (AbdAlrazaq A et al., 2020).

Social media platforms have also become helpful for the lay public to maintain communication with friends and family. In this way, it further helps in reducing the isolation and boredom during the period of isolation / quarantine, which have been associated with anxiety and long-term distress (Daniel et al., 2020). Therefore, it becomes an important recommendation for isolation at home or during quarantine, to help in reducing the psychological impact.

Social media usage has shown to be increased significantly in cases of natural disasters and crises (Gottlieb and Dyer, 2020), as information needs to be transferred quickly. This rapid dissemination overcomes barriers of traditional media into stakeholders including the public, healthcare systems and healthcare providers (HCPs). This has also come as an aid and an effective tool in making important decisions, as formal websites, traditional journals, and e-mail have their own peculiar communication deficiencies. As a result, social media channels became the most 
common resource on COVID-19 for scientist and public (Gupta et al., 2020; Hermida et al., 2012).

Recently, during this pandemic, some of the most relevant characteristics of social media platforms has been the rapid dissemination of protocols at regional, national, and international levels. Sharing protocols about treatment, personal protection equipment, or even proposals for fair allocation in scarce medical resource settings have now become the new normal (Emanuel et al., 2020).

This pandemic started an unexpected race to publish in medical journals, increasing plagiarism and poorly validated primary data (Ahmed, 2020). Most journals embarked on fast-track processing of COVID-19 submissions to prioritize and avoid delays in dissemination of potentially valuable scientific knowledge, sharing them as preprints, increasing and actively attracting social media mentions and citations by scientific community and public. However, at times, also giving a false impression of the global scholarly community approval leading to misinformation (Callaway, 2020; Kwon, 2020). Until now, social media channels are distinguished as the most important sources of information as well as misinformation (Gupta et al., 2020) becoming our biggest ally but also our biggest enemy. See Table 1.

Table 1: Positive and negative impact of social media in COVID - 19 pandemic era.

\begin{tabular}{|c|c|}
\hline POSITIVES & NEGATIVES \\
\hline $\begin{array}{ll}\text { For Public } \\
\text { - } & \text { Obtain } \\
& \text { Governme } \\
\text { nt } \\
\text { announces } \\
\text { rapidly } \\
\text { - } & \text { Keep up } \\
& \text { with the } \\
\text { health } \\
\text { informatio } \\
\mathrm{n} \\
\text { Easier to } \\
\text { follow the } \\
\text { governmen } \\
\mathrm{t} \\
\text { instruction } \\
\mathrm{s} \text { in the } \\
\text { manageme }\end{array}$ & $\begin{aligned} & \text { For Public } \\
& \text { - } \text { False } \\
& \text { information or } \\
& \text { manipulated } \\
& \text { content } \\
& \text { - } \text { Sponsored } \\
& \text { content } \\
& \text { - } \text { Not verified } \\
& \text { data shared by } \\
& \text { media } \text { influencers } \\
& \text { - } \text { Big volume of } \\
& \text { information } \\
& \text { from multiple } \\
& \text { platforms. }\end{aligned}$ \\
\hline
\end{tabular}

\begin{tabular}{|c|c|}
\hline nt of crises. & \\
\hline $\begin{array}{ll}\text { For } & \text { Health Care } \\
\text { Providers } \\
\text { - } & \text { Sharing } \\
& \text { key data } \\
& \text { rapidly, } \\
& \text { across } \\
& \text { geographic } \\
& \text { al } \\
& \text { boundaries } \\
\text { - } & \text { Decreased } \\
& \text { knowledge } \\
\text { translation } \\
\text { time. } \\
\text { Impact in } \\
\text { public } \\
\text { attitude } \\
\text { and raised } \\
\text { awareness. } \\
\text { Better } \\
\text { manageme } \\
\text { nt of crises } \\
\text { harnessing } \\
\text { social } \\
\text { media } \\
\text { tools. }\end{array}$ & $\begin{array}{ll}\text { For } & \text { Health Care } \\
\text { Providers } \\
\text { - } & \text { Big volume of } \\
& \text { information that } \\
& \text { becomes } \\
& \text { overwhelming } \\
\text { - } & \text { Tendency of } \\
& \text { information } \\
& \text { depending in } \\
\text { their core } & \text { beliefs. } \\
\text { - } & \text { Panic } \\
\text { transmission } \\
\text { - } \\
\text { Misinformation } \\
\text { and } \\
\text { Disinformation } \\
\text { A lot of low- } \\
\text { quality } \\
\text { information. }\end{array}$ \\
\hline
\end{tabular}

Source: Author's own study

\subsection{Our ally}

The COVID-19 pandemic is complex in nature as it has disproportionate effects on multiple groups of people. The virus is moving at varying speeds which demands the best of us and our management capabilities (Kathryn et al., 2021). Today users are harnessing social media tools to enhance organizational capacity and demonstrate resilience in response to crises. Social media users are creating new avenues for collaboration that likely will lead to more resilient communication over time (Almansoori and Habtoor, 2018). Social media provides an alternative that every health care system and healthcare provider needs to deliver quick, reliable information across geographical boundaries and time zones with clarity to address critical issues related to SARS-COV2 infection. Rapid response to the pandemic is imperative as HCPs do not have time to reflect on previous practice or rely on large scale randomized controlled trials (Kearsley and Duffy, 2020).

During a time when information changes quickly, it is critical for health care staff to stay 
up to date with the latest evidence. Social media can facilitate this unmet need. Social media allows for interaction in online journal clubs with experts sharing data on a global open-source platform, bookmarking content in specified web pages, and hosting webinars and video conferences. The decreased knowledge translation time provided by social media allows HCPs to analyse and debate the literature in real-time, addressing the internal and external validity of the findings (Gottlieb and Dyer, 2020).

This plethora of social media tools has changed the landscape of crisis management considerably over recent years. Clinicians are making a faster impact in public attitudes and behaviours, (e.g. self-isolating, handwashing, accessing health care), awareness about the disease and its symptoms, and more contributions to important decisions taken during the outbreak (e.g. quarantine measures, development of new vaccines, internationally coordinated responses) (Depoux et al., 2020).

Unlike traditional broadcast news, social media is a new dynamic way to obtain information, with capacity to interact between the emisor and the receivers in an immediate way.

Social media have the great advantage of rapid dissemination of educational content in the COVID-19 era, for example, Chan et al. (2020) developed an infographic about airway management of patients with suspected or confirmed COVID-19. It was shared through Twitter and WeChat, in few days requests were received for its translation into more than ten languages, besides the distribution allowed adapting the infographic to the particularities of each healthcare setting.

Faster dissemination of information regarding preventive measures has a lot of potentials. A recent study by Basch et al. (2020) evaluated the 100 most viewed videos on YouTube with the word "coronavirus", these together had more than 165 million views as of March 5, $2020,85 \%$ of them belonging to news channels; It was found that less than $1 / 3$ of the videos mentioned the recommended prevention measures, less than half mentioned the most frequent symptoms, however, almost 90\% commented on deaths, anxiety, and the quarantine status. This study leaves us with an important reflection on the missed opportunities for dissemination of quality information on the prevention of contagion and frequent symptom of COVID-19 on platforms such as YouTube, which are being increasingly consulted as an information source.

When it comes to publications, studies have shown that the dissemination of scientific literature on social media platforms (Facebook, Twitter, etc.) increases the number of downloads, queries, and citations of these articles (8 - 10) which, with the COVID-19 pandemic are characteristics that have undoubtedly allowed rapid dissemination of knowledge worldwide, in addition to markedly reduced editorial times, which have gone from months of processing to days or weeks since its reception.

Another advantage of social media platforms during the COVID-19 pandemic has been the possibility of arranging collaborative research projects, surveys, and multi-center studies. Finally, another advantage of social media platforms is supporting continued medical education through online live and recorded webinars through platforms like YouTube, Skype, or Zoom.

\subsection{Our enemy}

Social media can also be an enemy in addressing the response to a health pandemic. The volume of information is large and overwhelming and has been termed an "infodemic" (Jaffar Abbas et al., 2021). It has been reported that presenting multiple simultaneous methods of knowledge transmission introduces cognitive overload, confusion, and increases the chance of error (Oyebode, 2013).

Inside all the important late breaking data there is also misinformation and panic at the same velocity (Depoux et al., 2020). The ease through which inaccuracies and conspiracies can be repeated and perpetuated via social media and conventional outlets puts public health at a constant in the crosshairs. There may have been no way to prevent a global COVID-19 pandemic spread, but verified information is the most effective prevention against the disease of panic and misinformation (The Lancet, 2020). 
It is the responsibility of social media users to transfer the most trustworthy information during this period of uncertainty and squash recognized misinformation. The users are responsible for flagging fake information, so fact-checkers can help to stop the spread in the network of multiple users at the same time. This volume of flagged information related to COVID is so big that Cristina Tardáguila, Associate Director of the International Factchecking Network (IFCN), has called COVID-19 'the biggest challenge fact-checkers have ever faced'. Society relies on educated scientists and physicians to be leaders in delivering fact-based information to the public. For this reason, in times of crises it is important to be leaders in the conversation of social media to guide correct and helpful information and knowledge to the masses looking for answers.

For this reason, before sharing any information, we advise following some guidelines of responsible use of social media when disseminating information. These guidelines are summarised in table 2.

Table 2: Criteria for responsible use of information disseminating on social media.

Guidelines for responsible use of social media for disseminating information

1. To be leaders in the conversation of social media to guide correct and helpful information and knowledge to the masses.

2. Avoid providing medical advice in social media and abstain from giving recommendations not backed by evidence as this may confuse lay public.

3. Quality should be preferred over quantity when sharing information. Low-quality evidence is of little or no use in daily practice and may give unfounded hope.

4. Prefer dissemination through established professional platforms, or communication groups.

5. Provide source when sharing information. Abstain from sharing information without a clear and trusted source.

6. Declare conflicts of interest, if and when appropriate.

7. Abstain from sharing information that may only induce panic or anxiety.

Source: Author's own study

Among the disadvantages, we also have the possibility that information transmitted is not current, has not been subjected to peer review, is invalid, incorrect, not applicable to our environment, or even false.

Another big obstacle for social media and the dissemination of information are the "bubble filters", a concept coined by Eli Pariser in 2011, which tells us about a "personalized ecosystem" towards the user, in which the algorithms through the data collected from the same user, predict their preferences and yield results that are considered similar to the likes of that user. These bubbles produce a loop of similar content that prevents the user from seeing other different sources to contrast information (Basch, 2020). This concept applies to any scenario or illness that is consulted in internet search engines or on social media platforms such as Facebook and Twitter.

Finally, probably the worst face of social media is the potential to disseminate erroneous, alarmist, and exaggerated information that can cause fear, stress, depression, and anxiety in people with or without underlying psychiatric illnesses.

A study by Wang et al. (Teoh, 2020) in China, conducting an online survey with 1,210 responses, found that $53.8 \%$ of respondents considered the epidemic's psychological impact as moderate or severe; even a research group created and validated a scale called "Fear of COVID-19 scale" (Holone, 2016) to assess the level of stress and anxiety in the population and to establish appropriate measures to prevent sequels associated, such as post-traumatic stress disorder (PTSD) which was the most prevalent psychiatric sequelae after the Severe Acute Respiratory Syndrome (SARS) epidemic in Asia in 2003, followed by depressive disorders (Wang, et al. 2020). Other more severe diseases or events such as suicides have already been reported in some parts of the World like India, Britain, Germany, and Italy (Mak, et al. 2009)

\section{FACT BASED AND PEOPLE - Centered COVID - 19 Crisis Communication Strategy \\ COVID-19 affects people of all demographics} (Chen et. al 2020) It is difficult not to form an opinion about an enduring pan- demic that continues to threaten lives, livelihoods, and gross domestic product (GDP) (Wang, et. Al, 
2020). However, given the personal and economic consequences tied to biased and misleading (Basch et. Al, 2020) or blatantly false and malicious (Teoh, et. al, 2020) information, it is imperative for media professionals, health experts, and government officials to develop a fact-based, people centered (Ahorsu, et. al, 2020) COVID-19 crisis communication strategy. In the context of our study, fact- based and people-centered crisis communication strategy is defined as communication endeavors deliver facts that matter to the people without framing the numbers or statistics based on personal views or ulterior motives (e.g., political gains or economic interests).
This way, well-intentioned information can be effectively delivered to the public without unintended consequences. It is important to note that educational interventions might be also needed for healthcare professionals, as a growing body of re- search shows that healthcare professionals often lack necessary levels of knowledge or risk perception needed to be vigilant about COVID-19 misinformation or disinformation (Daniel, et. al. 2020) Considering the important role healthcare professionals serve in patient education and the fact that many healthcare professionals also face substantial mental health challenges (Verner, et. al, 2020) educational interventions may be incremental in addressing infodemic-induced challenges these frontline workers face.

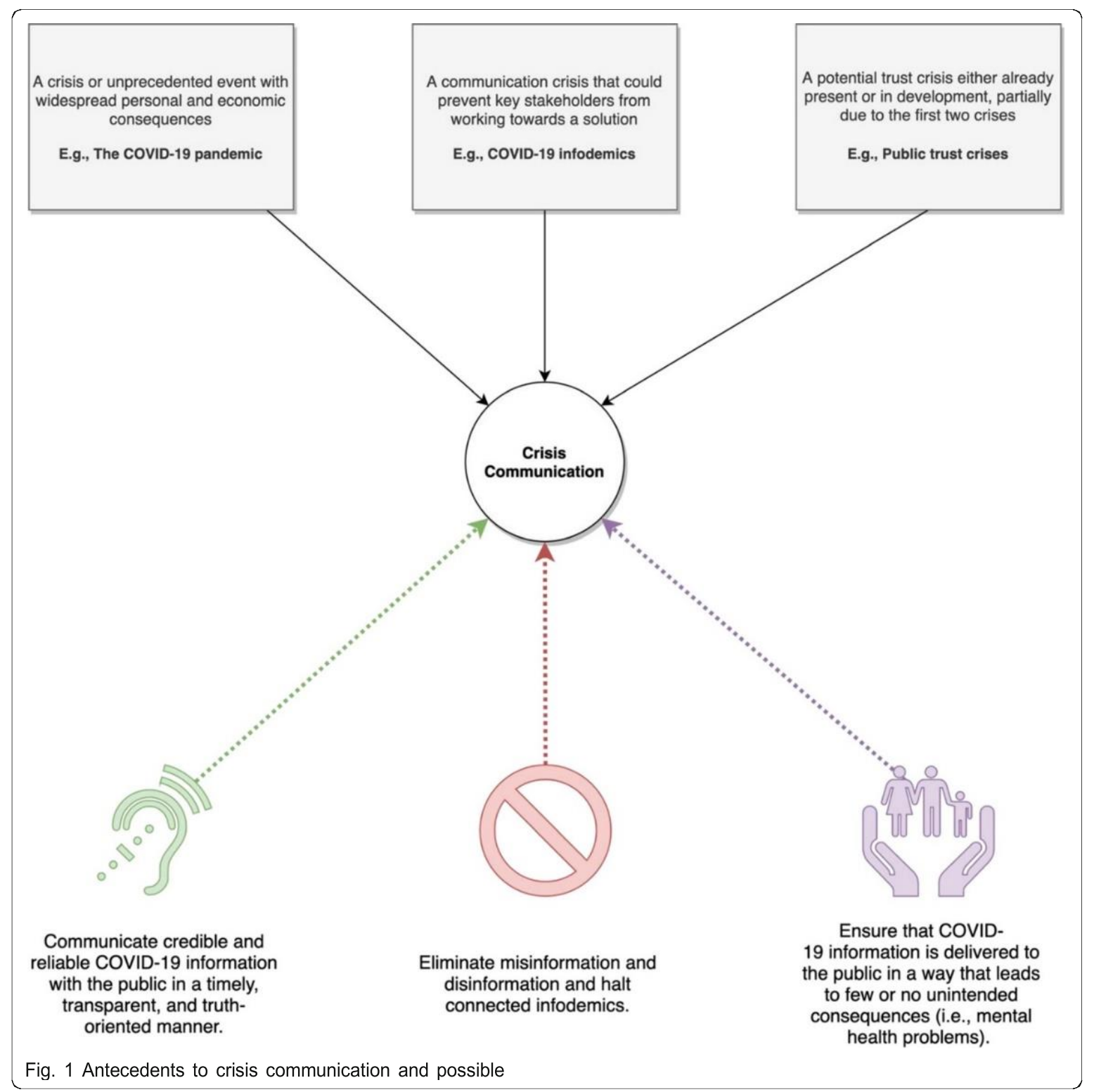




\section{DIGITAL FUTURES}

Has the COVID-19 pandemic accelerated digitisation the world over? A quick Google search shows that there are several whitecollar institutions that are considering this question and the future of what the workplace will look like. The scale of migrant worker crisis that India is currently facing suggests that any kind of digital transformation without building adequate infrastructure in the present is likely to be heavily exclusionary (Bhagyashree Barhate, 2021). This question of exclusion applies to a larger context as well. As schools and colleges are forced to go online, classes are being conducted over video, examinations have been rescheduled, countless "webinars" have been organised by universities, and some institutions have deliberated on "open-book" tests, indicating that conversation about how to envision the future of education has begun. Education is an "essential," along with finance and welfare. But not everyone might have the devices or the knowledge necessary to access these facilities remotely. Therefore, any strategy to move forward has to deal with the health crisis and the economic crisis in tandem. The digital space can be an indispensable resource in such a scenario. But it has to be made more inclusive.

Governments across the world recognise the power of digital infrastructure, and capacity building has been in progress throughout the last decade. In India, the "Digital India" campaign was launched in 2015 in order to make digital services available to the remotest areas. Furthermore, several welfare delivery mechanisms, such as the public distribution system, tried to migrate to the digital sphere. This was done by means of linking recipients' biometric information through Aadhaar and PAN to public welfare schemes. But, as several studies have repeatedly pointed out, our digital infrastructure and, indeed, our digital literacy has remained woefully inadequate, particularly in terms of the various dimensions of access.

In the following points, we have identified and highlighted some of the problems with digitisation in various essential sectors.

\subsection{Education Online}

The primary problem with online teaching is the issue of access. Literature on the issue outlines how access does not merely mean the availability of the internet, it also means access to appropriate devices, in addition to privacy. Most students, attend classes on their mobile phones, where the ability to concentrate for the duration of long lectures becomes limited owing to the size of the screen. Furthermore, such lectures tend to take up a lot of data that students buying limited data packs may not have access to.

\subsection{Financial Inclusion}

A 2014 survey on financial literacy in India found that only $24 \%$ of Indians are financially literate. The Digital India campaign had attempted to achieve financial inclusion through various initiatives like online banking and Permanent Account Number (PAN), Aadhaar cards, and by simplifying tax procedures. Despite that, World Bank data indicates that about 190 million adults in India do not have a bank account, making India the world's second-largest nation in terms of unbanked population after China. Even though the same report shows that $80 \%$ of Indians do have bank accounts, simply having an open account does not mean the account holders will be proficient in using online banking services.

\subsection{Access to Welfare}

Sankina Dhorajiwala (2020) writes that "link fail" is now a common term used across rural India. The term has a diverse range of meanings, from the internet not functioning to an Aadhaar failure. However, given that in the last decade, welfare programmes have attempted to migrate online for the ease of delivery, "link fail" has become a problem. The application, approval and implementation processes all depend on technological proficiency that neither official or recipients of programmes have in some cases.

\subsection{Healthcare}

There is little very research investigating the existing use, adoption, and efficacy of electronic health records (EHRs) in India. This is true, even for developed countries that have relied on EHRs for some time now. Consequently, the success of EHRs is doubtful. It is observed that the success of EHRs is dependent on a number of sociocultural factors, such as the doctorpatient ratio, nature of work, resource constraints that India already has, and 
technological inability. Furthermore, the risk of exclusion is inherent in delivering care to remote locations.

\section{IMPLICATION FOR RESEARCH AND PRACTICE}

In this section, we revisit some of the key issues that are important for research and practice. Further our discussion will be based upon the post - pandemic situation and the aspects of research discussed above.

\subsection{Implications for Research}

1. Many research issues arise with regards to work from home and gig work. This includes aspects of trust, measurement of performance, communication effectiveness and collaboration.

2. It can be expected that the dark side of virtual work and gig work, will raise questions of stress, work overload, surveillance, and monitoring. New and severe forms of digital surveillance will have to be understood and their implications gauged.

3. Though much work has been done in understanding the parameters and impact of the digital divide, it will be important to understand how those without access suffer more from the consequences of the pandemic when the world survives on digital communications and operations.

4. Management of the internet within countries is important, and aspects of enhancing networks include regulating zero-rating plans cautiously, seeing their implications for welfare, and how they can enhance access.

5. Internet shutdowns during and after a pandemic lead to severe difficulties for citizens, who have come to depend on these services. Research has to examine the direct, second-order, and third-order impacts of these shutdown measures.

\subsection{Implications for Practice}

1. Design of secure technologies, like blockchain-based applications, for the surge in online education and healthcare activities.
2. Policy for regulating digital infrastructure needed for increased digital transformation.

3. Design of technologies for managing secure online interactions - for education, healthcare, payments.

4. Design of apps for contract tracing and disease surveillance that balance privacy versus public health.

5. Managers will have to understand resistance to technology and ways to manage change, both among employees as well as customers.

6. Given the significant role which the internet is about to play in times to come, Internet intermediaries will work with government and civil society to address privacy and surveillance issues for better adoption of technology.

\section{CONCLUSIONS}

Social media is essential in the way we experience news and share medical information in this pandemic. Thanks to the algorithms and tools in social media platforms, it is possible to find the most relevant information inside the colossal volume of shared knowledge, and this allows us to take actions to make an impact in public healthcare. During this time when there is a sense of urge to maintain social distancing, quarantining, and staying in isolation and following various other COVID appropriate behaviours, the platforms allow us to interact between emisors and receivers, discussing the validity of the findings in the information shared with our network, quicker than 30 years ago.

But this positive side of social media also comes with a negative impact, the way misinformation travels is faster, hence is crucial to improve our systems understanding the flow of information between the stakeholders and do more to protect people from harmful content related to the pandemic. It is our responsibility as healthcare providers to help smashing the misinformation we found in social media, because even with artificial intelligence the fact checkers are being overwhelmed by the volume of information.

The responsible use of Social Media tools can help during the pandemic to quickly spread 
the new important information, sharing diagnostic, treatment and follow-up protocols, comparing different approaches from other parts of the world to adapt them to our setting and available resources, with downsize of possible dissemination of fake data, myths, and pessimist information that combined with quarantine states may lead to anxiety, depression and in extreme cases, the suicide. Therefore, it is advisable not to contribute to the infodemic and follow a responsible use of social media when disseminating information.

As the COVID - 19 pandemic forces several sectors into the digital space, India faces the danger of aggravating existing inequalities too, by excluding the large parts of population. Hence, there is an opportunity to grow as digital scientific community as well as digital lay public by equipping them with the required resources and accesses to deal with the post COVID -19 scenario which is a digital form of present scenario.

\section{REFERENCES}

Abd-Alrazaq A, Alhuwail D, Househ M, Hamdi M, Shah Z. (2020) Top Concerns of Tweeters During the COVID-19 Pandemic: Infoveillance Study. Journal of Medical Internet Research, 22 (4), 19016, doi: 10.2196/19016.

Ahmed, S. (2020) Letter to the editor: social media is a double-edged sword in the COVID-19 pandemic. Journal of Korean Medical Science 35, e270, doi: 10.3346/jkms.2020.35.e270

Ahorsu D K, Lin C Y, Imani V, Saffari M, Griffiths M D, Pakpour A H (2020), The Fear of COVID-19 Scale: Development and Initial Validation. International Journal of Mental Health Addict. March 27, 1-9, doi: 10.1007/s11469-020-00270-8

Almansoori, M. K. and Habtoor, N. (2018) The role of social media in crisis preparedness and responses. International Journal of Scientific and Engineering Research 9, 1347-1353

Basch C H, Hillyer G C, Meleo-Erwin Z C, Jaime C, Mohlman J, Basch C E (2020), Preventive Behaviors Conveyed on YouTube to Mitigate Transmission of COVID-19: Cross-Sectional Study, JMIR
Public Health Surveill, 6 (2), 18807, doi: 10.2196/18807

Bhagyashree Barhate, Malar Hirudayaraj, Noeline Gunasekara, Ghassan Ibrahim, Amin Alizadeh, Mehrangiz Abadi (2021), Crisis Within a Crisis: Migrant Workers' Predicament During COVID-19 Lockdown and the Role of Non-profit Organizations in India, Indian Journal of Human Development, 15 (1), 151-164, doi: $10.1177 / 0973703021997624$

B. J. Jansen, M. Zhang, K. Sobel, and A. Chowdury (2009), Twitter power: Tweets as electronic word of mouth," Journal of the American society for information science and technology, 60 (11), pp. 21692188, doi: 10.1002/asi.21149

Callaway, E. (2020) Will the pandemic permanently alter scientific publishing? Nature 582, 167-168

C. A. Cassa, R. Chunara, K. Mandl, and J. S. Brownstein (2013), Twitter as a sentinel in emergency situations: lessons from the Boston marathon explosions, PLoS Currents Disasters, 5 (1), doi: 10.1371/currents.dis.ad70cd1c8bc585e947 0046cde334ee4b.

Chan A K M, Nickson C P, Rudolph J W, Lee A, Joynt GM (2020), Social media for rapid knowledge dissemination: early experience from the COVID-19 pandemic, Anaesthesia, 75, 1579 - 1582, doi: 10.1111/anae.15057

Daniel A. González-Padilla, Leonardo Tortolero-Blanco (2020) Social Media Influence in the COVID - 19 Pandemic, Inte Braz J Urol, 46 (1), 120 -124, doi: 10.1590/S1677-5538.IBJU.2020.S121

Depoux, A., Martin, S., Karafillakis, E., Preet, R., Wilder-Smith, A. and Larson, $\mathrm{H}$. (2020) The pandemic of social media panic travels faster than the COVID-19 outbreak. Journal of Travel Medicine 27, issue 3, taaa031, doi: 10.1093/jtm/taaa031

Dhorajiwala, S. (2020) Who is Responsible When Technology Fails the Marginalised? Economic and Political Weekly 55 (21), ISSN (Online) - 2349-8846

Emanuel EJ, Persad G, Upshur R, Thome B, Parker M, Glickman A, et al. (2020) Fair Allocation of Scarce Medical Resources in 
the Time of Covid-19, The New England Journal of Medicine,382, 2049-2055, doi: 10.1056/NEJMsb2005114

Gasparyan A Y et al. (2015), Rewarding peer reviewers: maintaining the integrity of science communication. J Korean Med Sci 2015, $30 \quad(4), \quad 360-364$, doi: 10.3346/jkms.2015.30.4.360.

Gasparyan A Y. et al. (2017), Plagiarism in the context of education and evolving detection strategies, J Korean Med Sci, 32(8), $1220 \quad-\quad 1227, \quad$ doi: 10.3346/jkms.2017.32.8.1220

G. Blank and B. C. Reisdorf (2012), The participatory web: A user perspective on Web 2.0, Information, Communication \& Society, $15 \quad(4)$, 537-554, doi: 10.1080/1369118X.2012.665935

Gottlieb, M. and Dyer, S. (2020) Information and disinformation: social media in the COVID-19 crisis. Academic Emergency Medicine 27, 640-641, doi: 10.1111/acem.14036

Gupta, L., Gasparyan, A. Y., Misra, D. P., Agarwal, V., Zimba, O. and Yessirkepov, M. (2020) Information and misinformation on COVID-19: a crosssectional survey study. Journal of Korean Medical Science 35, e256, doi: 10.3346/jkms.2020.35.e256

Hermida, A., Fletcher, F., Korell, D. and Logan, D. (2012) Share, like, recommend. Journalism Studies 13, 815-824

Holone H. (2016), The filter bubble and its effect on online personal health information, Croatian Medical Journal, 57 (3), 298- 301, doi: 10.3325/cmj.2016.57.298

Jaffar Abbas, Dake Wang, Zhaohui Su, Arash Ziapour (2021), The role of Social Media in Advent of COVID 19 Pandemic: Crisis Management, Mental Health Challenges and Implications, Risk Management and Healthcare Policy, 14, 1917-1932, doi: 10.2147/RMHP.S284313

J. B. Houston, J. Hawthorne, M. F. Perreault, E. H. Park, M. Goldstein Hode, M. R. Halliwell, et al., "Social media and disasters: a functional framework for social media use in disaster planning, response, and research," Disasters, vol. 39, pp. 1-22, 2015
Kathryn Buchanan, Lara B. Aknin, Shaaba Lotun, Gillian M. Sandstrom (2021), Brief exposure to social media during the COVID-19 pandemic: Doom-scrolling has negative emotional consequences, but kindness-scrolling does not, PLoS ONE, 16 (10), doi: 10.1371/journal.pone.0257728

Kaplan, Andreas M. And Haenlein Michael (2010), Users of the World, Unite! The challenges and opportunities of social media, Business Horizons, 53(1), 59-68.

Kearsley, R. and Duffy, C. C. (2020) The COVID-19 information pandemic: how have we managed the surge? Anaesthesia 75, 993-996, doi:10.1111/anae.15121

K. Vance, W. Howe, and R. P. Dellavalle (2009), Social internet sites as a source of public health information, Dermatologic clinics, $27 \quad$ (2), 133-136, doi: 10.1016/j.det.2008.11.010.

Kwon, D. (2020) How swamped preprint servers are blocking bad corona virus research. Nature 581, 130-13

Lasorsa, Dominic L., Lewis, Seth C. And Holton, Avery E. (2012) 'Normalizing Twitter: journalism practice in an emerging communication space', Journalism Studies, 13 (1), 19-36.

M. N. K. Boulos, B. Resch, D. N. Crowley, J. G. Breslin, G. Sohn, R. Burtner, et al. (2011), Crowdsourcing, citizen sensing and sensor web technologies for public and environmental health surveillance and crisis management: trends, OGC standards and application examples, International Journal of Health Geographics, 10 , 67, doi: 10.1186/1476072X-10-67

Mak I W, Chu C M, Pan P C, Yiu M G, Chan V L (2009), Long-term psychiatric morbidities among SARS survivors, General Hospital Psychiatry, 31 (4), 318326, doi: 10.1016/j.genhosppsych.2009.03.001

McCauley M., Minsky S. \& Viswanath K. (2013), The H1N1 pandemic: media frames, stigmatization and coping, BMC Public Health, 13, 1116, doi: 10.1186/14712458-13-1116 
Misra D P et al. (2017), Plagiarism: Softwarebased detection and the importance of (Human) hardware. Indian Journal of Rheumatology, 12(4), 188-189.

M. N. K. Boulos, B. Resch, D. N. Crowley, J. G. Breslin, G. Sohn, R. Burtner, et al. (2011), Crowdsourcing, citizen sensing and sensor web technologies for public and environmental health surveillance and crisis management: trends, OGC standards and application examples, International Journal of Health Geographics, 10 , 67, doi: 10.1186/1476072X-10-67

N. B. Ellison, C. Steinfield, and C. Lampe (2007), The benefits of Facebook "friends:" Social capital and college students' use of online social network sites, Journal of Computer- Mediated Communication, 12 (4), 1143- 1168, doi: 10.1111/j.1083-6101.2007.00367.x

N. Dabner (2012), 'Breaking Ground' in the use of social media: A case study of a university earthquake response to inform educational design with Facebook, The Internet and Higher Education, 15 (1), pp. 69-78, doi: 10.1016/j.iheduc.2011.06.001

Oyebode, F. (2013) Clinical Errors and Medical Negligence, Medical Principles and Practice, 22, 323-333, doi: 10.1159/000346296

Pennebaker J.W. and Harber D. (1993), A Social Stage model of collective coping: The Loma Prieta earthquake and the Persian Gulf War, Journal of Social Issues, 49, 125145, doi: 10.1111/j.15404560.1993.tb01184.x

R. M. Merchant, S. Elmer, and N. Lurie (2011), Integrating social media into emergencypreparedness efforts, The New England Journal of Medicine, 365 (4), 289-291.

R. Piarroux, R. Barrais, B. Faucher, R. Haus, M. Piarroux, J. Gaudart, et al. (2011), Understanding the cholera epidemic, Haiti, Emerging infectious diseases, 17 (7), 1161-1168, doi: 10.3201/eid1707.110059

Shailendra Palvia, Prageet Aeron, Parul Gupta, Diptiranjan Mahapatra, Ratri
Parida, Rebecca Rosner \& Sumita Sindhi (2018), Online Education: Worldwide Status, Challenges, Trends, and Implications, Journal of Global Information Technology Management, 21(4), 233-241, doi: 10.1080/1097198X. 2018.1542262

Teoh J Y, Mackenzie G, Tortolero L, Rivas J G. (2020), Social Media Analytics: What You Need to Know as a Urologist, Eur Urol Focus, 6 (3), 434-436, doi: 10.1016/j.euf.2019.08.005

The Lancet. (2020) COVID-19: fighting panic with information. Lancet 395, 537. doi: 10.1016/S0140-6736(20)30379-2

T. Simon, A. Goldberg, and B. Adini (2015), Socializing in emergencies - A review of the use of social media in emergency situations, International Journal of Information Management, 35 (5), pp. 609619, doi: 10.1016/j.ijinfomgt.2015.07.001

Verner Venegas-Vera, A., Gates B Colbert, Edgar V. Lerma (2020) Positive and Negative Impact of social media in the COVID - 19 Era, Reviews in Cardiovascular Medicine, 21 (4), 561 564, doi: 10.31083/j.rcm.2020.04.195

Wang C, Pan R, Wan X, Tan Y, Xu L, Ho CS, et al. (2020), Immediate Psychological Responses and Associated Factors during the Initial Stage of the 2019 Coronavirus Disease (COVID-19) Epidemic among the General Population in China. International Journal of Environmental Research and Public Health, 17 (5), 1729.

World Health Organization. Coronavirus disease (COVID-19): Situation Report 120. Available at: https://www.who.int/docs/defaultsource/coronaviruse/situationreports/20200519-covid-19-sitrep120.pdf?sfvrsn=515cabfb_4

Zhaohui Su et al. (2021), Mental health consequences of COVID-19 media coverage: the need for effective crisis communication practices, Globalization and Health, 17 (4), doi: 10.1186/s12992020-00654-4 